\title{
Effect of interfacial variables on metal-porcelain bonding
}

\author{
Warren C. Wagner* and Kamal Asgar \\ Department of Biologic and Materials Sciences, 2211 School of Dentistry, University of Michigan, Ann Arbor, \\ MI 48109-1078 \\ W.C. Bigelow and Richard A. Flinn \\ Department of Materials Science and Engineering, School of Engineering, University of Michigan, Ann Arbor, MI.
}

While ceramic-to-metal bonding has been used in many applications, the actual chemical and physical factors leading to optimum bond strength are not well understood. In this work, several variables affecting the bonding between dental porcelain and a palladium alloy $(85 \% \mathrm{Pd}, 10 \% \mathrm{Cu}$, and $5 \% \mathrm{Ga})$ were investigated: 1) precoating the metal by sputtering various oxides before porcelaining; 2) preoxidation of the metal base before porcelaining; 3) porcelaining under reducing atmosphere; and 4) surface roughening at controlled levels before porcelaining.

Using a modification of the push doughnut shear bond strength test to measure bond strength the following results were obtained. 1) Compared with standard "control" samples, the aluminum oxide precoated specimens showed a bond strength improvement of $46 \%$, while the copper, manganese, and tin oxide precoatings exhibited smaller effects. 2) Preoxidation of the metal base led to pronounced bond strengthening $(152 \%)$ by surface roughening as well as oxide formation. 3) Porcelaining under a reducing atmosphere severely reduced bond strength ( $88 \%$ lower than the controls) indicating the role of oxidation during the standard firing cycle. 4) Mechanical roughening of the surface by controlled amounts gave pronounced improvements with greater notch depth. Coarse roughening produced the highest bond strength improvements $(486 \%)$. (c) 1993 John Wiley \& Sons, Inc.

\section{INTRODUCTION AND OBJECTIVES}

Dental research in ceramic-to-metal bonding has focused on two areas. First, the development and testing of alloy-porcelain systems for crowns and bridges and second, more basic research to understand the physical mechanisms involved in the bonding. The present study falls within the latter area.

There are three main factors that determine the success of a ceramic-metal bond: residual stress gradients, interfacial chemistry, and the interfacial morphology.

Much of the basic research has concentrated on residual stresses and thermal expansion compatibility. With large differences in thermal expansion coefficients, residual stress gradients will form across the interface during processing. These stresses can be so strong that either the bond fails at a much lower stress level or the porcelain spontaneously spalls off. Generally we attempt to limit differences in thermal

*To whom correspondence should be addressed.

This article is derived from The Effect of Interfacial Variables on Metal-Porcelain Bonding, Warren C. Wagner, Doctoral Thesis, The University of Michigan, 1990. expansion coefficients between the ceramic and the metal. In this research the thermal expansion coefficients of the alloy and ceramic were matched to isolate the other factors-interfacial chemistry and interfacial morphology.

Researchers over the past 50 years have attempted to determine the chemical nature of the interface formed between ceramics and metals. Several theories ${ }^{1-16}$ have been put forward; however, relatively little physical evidence has been available to support those theories.

Theories of the effects of interfacial morphology have been mixed. ${ }^{17,18}$ Some researchers believe that rough interface morphologies improve bond strength by mechanical attachment or by increased area for chemical bonding. However, others believe that roughness can weaken the interface by causing stress concentrations that could initiate fracture and others believe that roughness could cause incomplete contact between the metal and ceramic (and trapped gases), which could also reduce bond strength.

The purpose of this study was to determine relative effects of a range of interfacial treatments which fall 
within two categories: modifying the chemistry of the interface or modifying the morphology of the interface. In general, the purpose was to develop techniques that could be used to improve ceramicto-metal bonding for porcelain-fused-to-metal dental crowns and bridges.

\section{MATERIALS AND METHODS}

\section{Alloy and porcelain}

To simplify interface reactions a single phased alloy with simple composition was necessary. It was also desirable for practical significance for the alloy to have similar composition to available dental alloys. Several alloys were developed and tested. An alloy composed of $\mathrm{Pd}-10 \% \mathrm{Cu}-5 \% \mathrm{Ga}$ was found to meet the requirements. The composition of this alloy is similar to that of the Pd-Cu dental alloys, examples of which include Liberty (J.F. Jelenko \& Co., Div. Pennwalt Corp., Armonk, NY), Natural Lite (Jeneric Industries, Inc., Wallingford, CT), Option (J.M. Ney Co., Bloomfield, CT), and Spartan (Williams Dental Co., Inc., Buffalo, NY). The specimens were cast using standard dental techniques; then the specimens were finished to a $1 \mu \mathrm{m}$ diamond polish before surface treatment.

The ceramic used in this study was a dental porcelain (Vita VMK 68531 opaque porcelain, Vita Zahnfabrik, H. Rauter $\mathrm{GmbH} \& \mathrm{Co}$. KG, Bad Säckingen, West Germany). It was applied to the alloy specimens (after the surface treatments) using standard dental porcelaining technique. For the mechanical test four layers of porcelain were applied and fired to build up the required thickness. The porcelain was fired using the manufacturer's directions for this porcelain.

\section{Surface treatments}

Precoatings. Several techniques to apply oxide precoatings were investigated and radio frequency sputtering was found to be most suitable. ${ }^{19-22}$ Specimens were sputter cleaned to remove any contaminants or oxides from the alloy surface. Then they were precoated with $\mathrm{Al}_{2} \mathrm{O}_{3}, \mathrm{Mn}_{2} \mathrm{O}_{3}, \mathrm{CuO}$, or $\mathrm{SnO}_{2}$ thin films (before the porcelain coating application). These oxides were chosen for their differences in physical properties. The primary properties of interest were the mechanical properties (based on hardness) and the stability (based on free energy of formation): $\mathrm{CuO}$ has the lowest hardness and stability, while $\mathrm{Al}_{2} \mathrm{O}_{3}$ has the highest hardness and stability. There are many other oxides that could be tested using these procedures. The standard precoating thickness was $100 \mathrm{~nm}$; however, with the $\mathrm{Al}_{2} \mathrm{O}_{3}$ specimens three coating thicknesses were tested.
Furnace Treatments. There were two furnace treatments: preoxidation of the alloy before porcelain application, and porcelain firing under reducing conditions. To preoxidize specimens, alloy rods were placed in the furnace, heated to $982^{\circ} \mathrm{C}$, and held in air for $5 \mathrm{~min}$ before porcelain application. This treatment produced a heavily oxidized surface. To eliminate the effect of oxidation, another set of specimens was coated with porcelain and fired under the reducing conditions of a $95 \%$ argon-5\% hydrogen atmosphere. The specimens were placed in the furnace, a vacuum of 1 torr was applied, and the specimens were heated to $260^{\circ} \mathrm{C}$ and held for $1 / 2 \mathrm{~h}$ to drive off water. Then the $\mathrm{Ar}-5 \% \mathrm{H}$ atmosphere was introduced at a flow rate of $150 \mathrm{cc} / \mathrm{min}$ and maintained throughout the firing cycle. The specimens were heated as with the normal firing cycle. However, after attaining the peak temperature, the specimens were then moved to a cool portion of the furnace and allowed to cool under the protective Ar-5\% $\mathrm{H}$ atmosphere.

Roughness. A series of specimens with progressively rougher surfaces was prod

uced. The methods used to make these were: a) centerless grinding using 400 grit $\mathrm{SiC}$ paper; b) sand blasting with $25 \mu \mathrm{m}$ alumina grit; and c) grooving with $1 \mathrm{~mm}$ deep and $1 \mathrm{~mm}$ wide cuts around the specimens. These were compared with the standard finish of $1 \mu \mathrm{m}$ diamond polish.

\section{Shear bond strength testing}

There have been many mechanical tests developed for measuring the adhesion between ceramics and metals. For this study a simple shear test was chosen. As indicated by Anusavic et al. ${ }^{23}$ the actual bond strength is difficult to determine with these tests because of nonuniform stress distributions. However, for this research the actual bond strength was not as important as the relative bond strengths resulting from the various treatments. In addition, the same alloy and porcelain were used for all specimens. Therefore the effects of thermal expansion incompatibility and differences in elastic moduli on bond strength were identical for all specimens and can be ignored when comparing the various treatments.

The bond strength test used in this research was a modification of the push doughnut test developed by Shell and Nielson and then later Asgar. ${ }^{24,25}$ The configuration of the test is shown in Figure 1. A $10 \mathrm{~mm}$ by $5 \mathrm{~mm}$ doughnut (torus) of porcelain was fired onto a $45 \mathrm{~mm}$ by $3 \mathrm{~mm}$ alloy rod. After the porcelain doughnut was fired in place on the rod, the area of the rod not covered by the porcelain was coated with a thin layer of wax (the wax prevented adhesion between the alloy rod and the stone). Then the rod and porcelain were encased in dental stone, a high-strength plaster of paris. The upper 




Figure 1. Configuration of the push doughnut test for measuring shear bond strength.

end of the rod was loaded in axial compression in a standard compression testing machine with a selfaligning head. Fracture occurred in shear between the doughnut of porcelain and the metal. Significance of differences in bond strength between materials were verified using ANOVA and the Bonferroni $t$ procedure (both at $P \leq .05$ ).

\section{Interface examination}

Scanning electron microscopy (SEM) and transmission electron microscopy (TEM) were used to observe fractured and intact specimens. Both microscopes were equipped for energy dispersive $x$-ray spectroscopy.

\section{RESULTS}

\section{Effects of interface chemistry on bond strength}

As shown in Table I, all the oxide precoatings improved bond strength over the controls (the controls had no precoatings, just polished surfaces). Statistically significant improvements were found with the $\mathrm{Al}_{2} \mathrm{O}_{3}$ precoatings, which improved bond strength by $46 \%(P \leq .05)$. Greater thickness of the Al precoatings improved bond strengths even further. The other oxides improved the bond strength by $24 \%$ for $\mathrm{SnO}_{2}$, and by $32 \%$ for $\mathrm{Mn}_{2} \mathrm{O}_{3}$ and $\mathrm{CuO}$, but these improvements were not statistically significant.

Next a technique commonly used in dentistry, preoxidation, was tried. Here the formation of a heavily oxidized surface resulted in a $152 \%$ improvement in bond strength (statistically significant at $P \leq .05$ ). This improvement is probably not solely due to the change in interface chemistry, but may be due to increased interface roughness (as will be discussed later).

It was found that the alloy in all the previous cases oxidized during porcelaining. Therefore, to eliminate the effect of oxidation, uncoated polished specimens were fired under the reducing conditions of an Ar$5 \% \mathrm{H}$ atmosphere. This resulted in very significant reductions in bond strengths $(-88 \%)$.

\section{Effects of roughness on bond strength}

Evidence both from electron microscopy of the previously mentioned specimens and from the

TABLE I

Bond Strengths Resulting from Various Treatments

\begin{tabular}{|c|c|c|c|}
\hline Treatment & $\begin{array}{c}\text { Bond Strength } \\
(\mathrm{MPa})\end{array}$ & $\begin{array}{c}\text { Standard Deviation } \\
(\mathrm{MPa})\end{array}$ & Sample Size \\
\hline Control & 23.7 & 3.9 & 7 \\
\hline Preoxidized & 59.7 & 13.1 & 7 \\
\hline \multicolumn{4}{|l|}{$100 \mathrm{~nm}$ oxide precoatings } \\
\hline $\mathrm{SnO}_{2}$ & 29.5 & 11.4 & 6 \\
\hline $\mathrm{Mn}_{2} \mathrm{O}_{3}$ & 31.3 & 8.5 & 5 \\
\hline $\mathrm{CuO}$ & 31.3 & 2.2 & 3 \\
\hline $\mathrm{Al}_{2} \mathrm{O}_{3}$ & 34.6 & 5.7 & 7 \\
\hline \multicolumn{4}{|l|}{$\begin{array}{l}\text { Increased thickness of } \\
\text { precoating }\end{array}$} \\
\hline $\mathrm{Al}_{2} \mathrm{O}_{3}, 100 \mathrm{~nm}$ & 34.6 & 5.7 & 7 \\
\hline $\mathrm{Al}_{2} \mathrm{O}_{3}, 175 \mathrm{~nm}$ & 39.0 & 7.8 & 5 \\
\hline $\mathrm{Al}_{2} \mathrm{O}_{3}, 350 \mathrm{~nm}$ & 46.9 & 2.6 & 2 \\
\hline \multicolumn{4}{|l|}{ Roughness series } \\
\hline Control & 23.7 & 3.9 & 7 \\
\hline 400 grit $\mathrm{SiC}$ paper & 64.5 & 6.1 & 6 \\
\hline Sandblasted & 81.1 & 2.2 & 2 \\
\hline Notched & 139.0 & 4.1 & 3 \\
\hline \multicolumn{4}{|c|}{ Reducing atmosphere series } \\
\hline Control, reduced & 2.9 & & 1 \\
\hline $\mathrm{Al}_{2} \mathrm{O}_{3}$, reduced & 2.6 & & 1 \\
\hline Preoxidized, reduced & 15.7 & & 1 \\
\hline Sandblasted, reduced & 25.0 & & 1 \\
\hline
\end{tabular}


literature indicates that roughening the interface will affect bond strength. Therefore a series of specimens with different interfacial roughness was tested. Table I shows that there is a strong correlation between the roughness and bond strength. The roughest finish showed the highest bond strengths $(139.0 \mathrm{MPa}$, $486 \%$ higher than the controls), while the smoothest finish showed much lower bond strengths (controls, $23.7 \mathrm{MPa})$.

\section{Effects of combined treatments}

All specimens (controls, precoated, or roughened) that were fired under the reducing atmosphere showed lower bond strengths than their counterparts fired under "normal" conditions. This change in strength ranged from a 13-fold decrease in strength for $\mathrm{Al}_{2} \mathrm{O}_{3}$ precoated specimen to a 3-fold decrease in strength for a sandblasted specimen. As expected, the decrease in bond strength from firing under the reducing conditions were more pronounced for specimens with smooth interfaces.

\section{Examination of interface structures}

Before porcelaining, the specimens were examined using SEM. They showed varying degrees of roughness as a result of the different pretreatments. The control specimens and sputter precoated specimens had very smooth finishes while the preoxidized specimens and the roughness series had greater surface roughness.

After porcelaining, the specimens were viewed in cross-section using SEM and TEM. Interfaces appeared intact in all cases. However, several features should be noted. The sputtered films dissolved into the porcelain and were no longer identifiable even at very high magnifications (Fig. 2). All the specimens fired under the "normal" atmosphere showed some degree of internal oxidation at the surface of the alloy. The internally oxidized layer (Fig. 3), showed large amounts of gallium oxide (as determined by energy dispersive $x$-ray spectroscopy). The formation of this oxide caused significant roughening of the surface of the alloy. Greater amounts of internal oxidation were observed with the preoxidized specimens, while the specimens fired under the $\mathrm{Ar}-5 \% \mathrm{H}$ atmosphere showed no internal oxidation.

Fractured cross-sections were observed after mechanical testing. In all specimens that had relatively smooth finishes, the fracture occurred primarily at the interface between the metal and the porcelain, with a few small islands of porcelain adhering to the alloy fracture surface (Fig. 4). However, with specimens that had coarse finishes (sandblasted and notched) in-

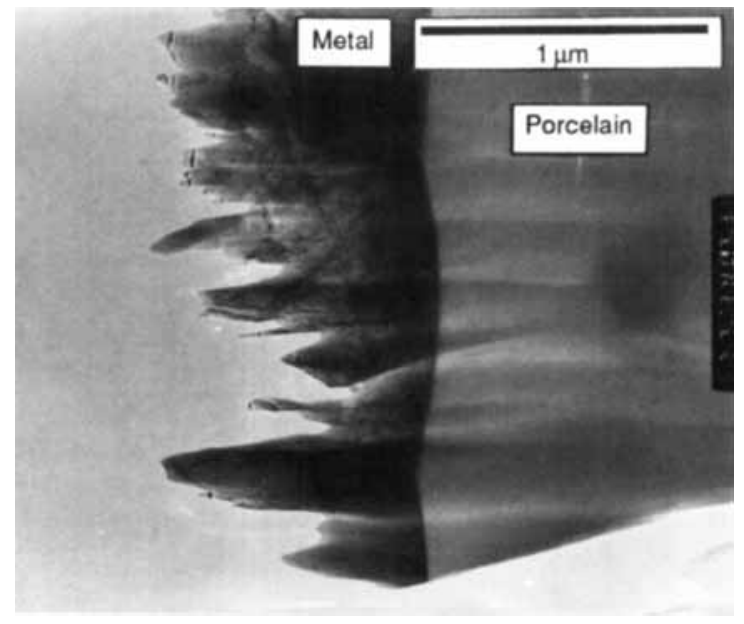

Figure 2. Cross-section of preoxidized specimen before porcelaining, showing the gallium oxide phase formed in the metal (the medium gray phase).

creased amounts of adherent porcelain were observed with the increased roughness (Fig. 5).

\section{DISCUSSION}

\section{Mechanical effects}

Roughening the alloy surface was the most effective treatment for improving bond strength. The roughest surface treatment, cut notches, produced 139.0 MPa bond strengths. This value is very close to the published shear strength of dental porcelains and examination of the fractured interface showed that most of the fracture actually occurred in the porcelain (Fig. 6). A less rough surface (sandblasted) showed similar effects although to a lesser degree. The other

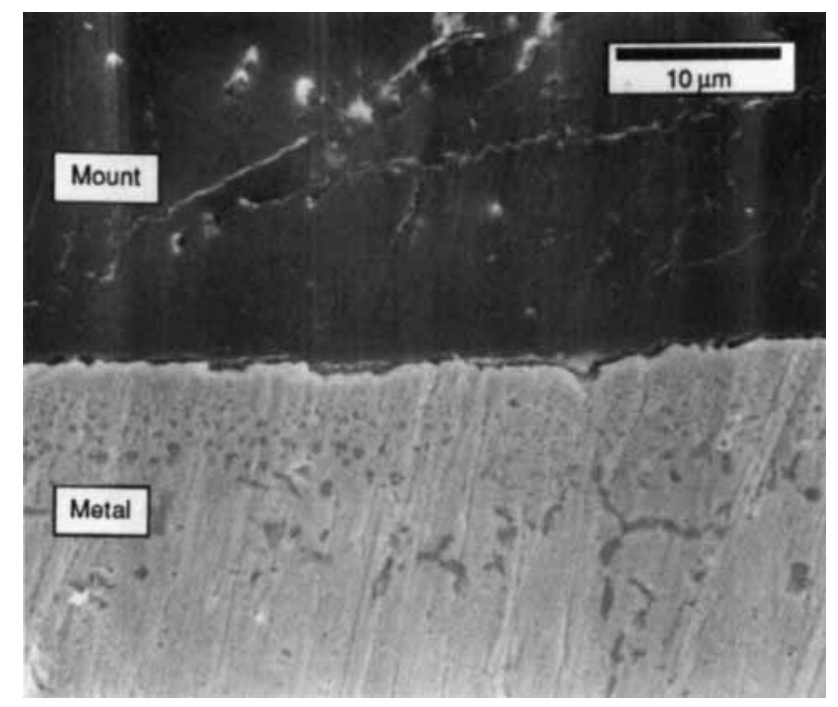

Figure 3. Transmission electron micrograph at $35,000 \times$ magnification. No second phases or sputtered films are visible at the porcelain-metal interface. 


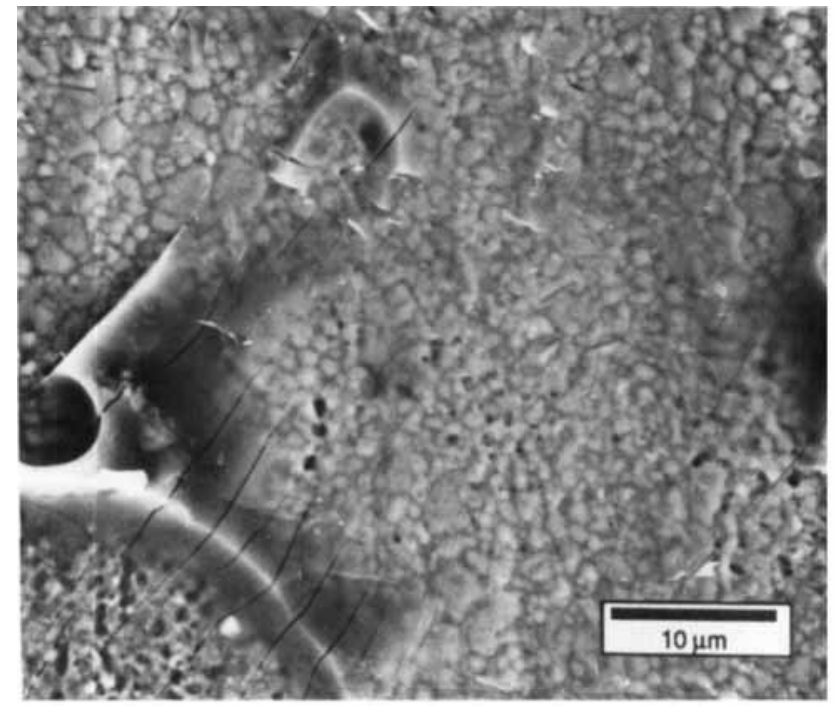

Figure 4. SEM of control specimen fracture surface showing islands of adhering porcelain on metal.

specimens with smoother surfaces all showed fracture at the interface with little adherent porcelain on the alloy fracture surface (Fig. 7).

The mechanism responsible for this strength increase is probably that the roughness causes the fracture path to deviate into the porcelain. When the shear strength of the porcelain is stronger than that of the interface, and fracture occurs in the porcelain (as with the rougher specimens), the bond strength is increased. In addition, interfacial roughness causes the fracture path to deviate, increasing the fracture surface area and the total energy required for failure.

There was no evidence of the maladies cited in the literature, either stress raisers caused by rough interface or trapped gases in the valleys, causing lowered

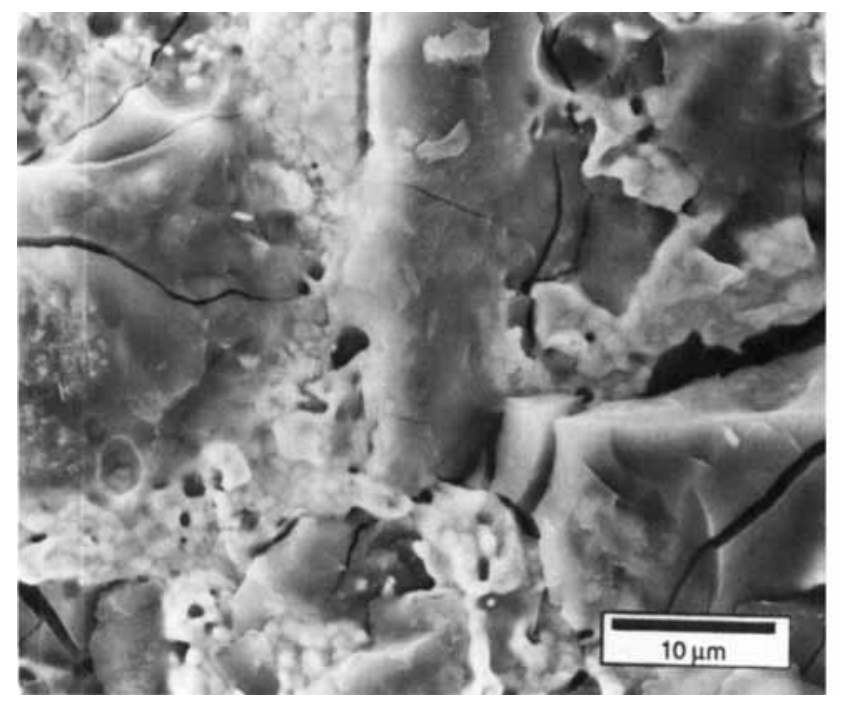

Figure 5. SEM of sandblasted specimen fracture surface showing large amounts of adhering porcelain.



Figure 6. SEM of cross-section of notched specimen after shear testing. Most of the fracture occurred in the porcelain.

bond strengths. Instead, it appears that the roughness is entirely beneficial to porcelain-metal bonding.

\section{Chemical effects}

Before continuing, it should be pointed out that no specimens showed a second phase along the interface except for the gallium oxide phase formed in the alloy near the interface (Fig. 2). This was established using electron microscopy (TEM or SEM) at magnifications to $160,000 \times$ (Fig. 3).

Perhaps the most significant outcome of this study was the effect of furnace atmosphere. Here 3- to 13-fold differences in bond strength were found depending on the history of the specimens. Firing in



Figure 7. SEM of cross-section of control sample showing only small amounts of adherent porcelain. 
an argon-5\% hydrogen atmosphere produced much weaker bonding in all cases that produced by the standard firing atmosphere (the hydrogen in the argon-5\% hydrogen atmosphere immediately removes any free oxygen that could become involved in reactions at the interface). This indicates that the presence of oxygen is critical for strong bonding.

While some of the effects of the reducing atmosphere may have been due to changes in the porcelain itself, this probably plays only a minor part in the reduced bond strength. The porcelain rarely fractured in specimens fired under the reducing atmosphere (only with the roughest specimens), and qualitative (indenter crack) fracture toughness tests showed only a minor decrease in the porcelain's fracture toughness.

Preoxidizing specimens resulted in substantial improvements in bond strength. Electron microscopy of the interface (Fig. 3) showed an internally oxidized structure consisting of a gallium oxide phase within $20 \mu \mathrm{m}$ of the surface of the alloy. In addition, it was found that porcelain penetrated into the metal where the phase was present at the surface. These results show that the preoxidizing process causes internal oxidation and roughening of the alloy surface. The approximate roughness (as determined by SEM) created by preoxidation is close to that created by the 400 grit $\mathrm{SiC}$ paper roughening treatment. The bond strengths are also close, which indicates that the improvement in bond strength after preoxidation is primarily caused by roughening, not the presence of additional oxides.

The improvements in bond strength with the $100 \mathrm{~nm}$ oxide precoated specimens ranged from $24 \%$ to $46 \%$ over the controls. Observation of the interface indicates that the precoatings completely dissolved into the porcelain, although they may persist at the atomic level at the interface. Therefore, it seems likely that the precoatings had a transient effect during the porcelain firing or perhaps a change in porcelain composition was responsible for the improvements in bond strength. Another factor should be considered-the specimens were sputter cleaned before the precoatings were applied and this has been shown to slightly improve bonding.

Other researchers have also observed improved bond strengths as a result of oxide precoating. McLean and Sced ${ }^{26}$ electroplated a variety of metal coatings on $\mathrm{Pt}$, which were subsequently thermally oxidized. The oxidized coatings of $\mathrm{Sn}, \mathrm{In}, \mathrm{Co}, \mathrm{Ni}$, and $\mathrm{Zn}$ produced the strongest bond strengths to porcelain. Allard ${ }^{27}$ reactive ion plated $\mathrm{SnO}_{2}$ and $\mathrm{Al}_{2} \mathrm{O}_{3}$ coatings onto base metal specimens followed by applying porcelain and found improved bonding with $\mathrm{Al}_{2} \mathrm{O}_{3}$, but not with the $\mathrm{SnO}_{2}$. Most recently Bullard et al. ${ }^{28}$ sputter deposited coatings of $\mathrm{Al}_{2} \mathrm{O}_{3}$, In, and $\mathrm{Sn}$ on a dental gold alloy (the In and $\mathrm{Sn}$ coatings were subsequently oxidized).
They found significant improvements in adhesion of porcelain with $\mathrm{Al}_{2} \mathrm{O}_{3}$ and $\mathrm{In}_{2} \mathrm{O}_{3}$, but not with $\mathrm{SnO}_{2}$.

While the techniques to apply the coatings and the metal substrates differ in these studies and our research, there is general agreement that $\mathrm{Al}_{2} \mathrm{O}_{3}$ coatings significantly improve bonding. Others have shown that In coatings can significantly improve bonding. The strong improvements in bond strength observed by McLean and $S_{c e d}{ }^{25}$ with $S n$ coatings was not observed by any other group; however, their coating thicknesses were about five times thicker than the rest.

\section{Combined chemical and mechanical effects}

To determine the mechanisms by which the various treatments affected bonding, some were combined. Most importantly, the effects of a reducing atmosphere in combination with other treatments were tested.

To compare the effects of roughness to that of porcelain firing atmosphere, specimens were sandblasted, porcelain was applied, and then the specimens were fired in the Ar-5\% $\mathrm{H}$ atmosphere. Here a large decrease in bond strength was found $66 \%$ lower than samples fired under normal conditions), although this bond strength was still much higher than that of the control fired under the same conditions. This shows that both firing atmosphere and roughness are important in determining the bond strength.

Preoxidation followed by firing in the Ar-5\% $\mathrm{H}$ atmosphere caused a $74 \%$ reduction in bond strength over preoxidized samples fired in the "normal" atmosphere. The oxides that had been on the surface appeared to be reduced, producing a metallic appearing surface. However, the surface had a frosted appearance-perhaps roughness produced by the preoxidation treatment. Again the data indicate the importance of both roughness and firing atmosphere.

\section{CONCLUSION}

Roughened surfaces resulted in the highest bond strengths. A direct correlation between roughness and bond strength was found with greater roughness leading to higher bond strength.

Changing porcelain firing atmosphere strongly affected bond strength. Firing in a reducing atmosphere $(\mathrm{Ar}-5 \% \mathrm{H})$ dramatically reduced bond strength (reductions between $69 \%$ and $88 \%$ ) as compared to specimens fired in a "normal" firing atmosphere. The amount of strength decrease was dependent on the pretreatment.

All sputtered oxide precoatings improved bond strengths over the controls. However, the only statistically significant increase was with the $\mathrm{Al}_{2} \mathrm{O}_{3}$ films, which produced a $46 \%$ improvement. Increasing 
the thickness of these $\mathrm{Al}_{2} \mathrm{O}_{3}$ precoatings improved the strength even further.

Preoxidizing the specimens improved bond strength $152 \%$. The preoxidation treatment resulted in the formation of an internal oxide, gallium oxide, and roughening of the interface between the alloy and porcelain.

Several people were very helpful or essential in the development of the techniques used in this project. Hal Estry provided the electronics knowledge required for designing the radio frequency sputterer. Haru Wada and Leya Wang supplied the hydrogen furnace and help in using it. The dental technology expertise of Edward R. Dootz and Gary $P$. Mora was indispensable for many phases of this project.

Partial funding for this research project was provided by National Institute of Dental Research Grant DE-04883.

\section{References}

1. M. Rühle and A. G. Evans, "Structure and chemistry of metal/ceramic interfaces," Mat. Res. Soc. Symp. Proc., 120, 293-311 (1988).

2. A.W. Hull and E. E. Berger, "Glass to metal seals," Ceram. Abstracts, 14, 136 (1935).

3. M.P. Borom and J. A. Pask, "Role of "adherence oxides' in the development of chemical bonding at glass-metal interfaces," J. Am. Ceram. Soc., 49, 1-6 (1966).

4. J.J. Brennan and J. A. Pack, "Effect of composition on glass-metal interface reactions and adherence," J. Am. Ceram. Soc., 56, 58-62 (1973).

5. C.I. Helgesson, Ceramic to metal bonding, Boston Tech. Publ. Inc., Cambridge (1968).

6. B. W. King, H. P. Tripp, and W. H. Duckworth, "Nature of adherence of porcelain enamels to metals," J. Am. Ceram. Soc., 42, 504-525 (1959).

7. W.D. Kingery, "Role of surface energies and wetting in metal-ceramic sealing," Ceram. Bul., 35, 108-112 (1956).

8. J.T. Klomp, "Interfacial reactions between metals and oxides during sealing," Ceram. Bul., 59, 794 802 $(1980)$.

9. J. A. Pask and R.M. Fulrath, "Fundamentals of glass-to-metal bonding, VIII," J. Am. Ceram. Soc., 45, 592-596 (1962).

10. J. A. Pask, Fundamentals of wetting and bonding between ceramics and metals, DHEW Publ. No (NIH) 77-1227, Washington, D.C. (1977).

11. J. Pask and A. Evans, Surfaces and interfaces in ceramic and ceramic-metal systems, Plenum Press, New York (1980).
12. J. A. Pask, "From technology to the science of glass/metal and ceramic/metal sealing," Ceram. Bul., 66, 1587-1592 (1987).

13. A.P. Tomsia and J. A. Pask, "Chemical reactions and adherence at glass/metal interfaces: an analysis," Dent. Mater., 2, 10-16 (1986).

14. L.H. Van Vlack, "The metal-ceramic boundary," Met. Eng. Quart., 5, 7-12 (1965).

15. J. Jach, A. Joshi, and D. Sengupta, Semiconductors and insulators, 5, 111 (1980).

16. J.W. McLean, Prosth. Dent., 31, 691-694 (1974).

17. J.W. McLean, "Physical and chemical characteristics of alloys used for ceramic bonding," in Dental porcelain: state of the art-1977, H.N. Yamada (ed.), University of Southern California School of Dentistry, Los Angeles, pp. 79-84 (1977).

18. J. M. Carter, J. Al-Mudafar, and S. E. Sorenson, "Adherence of a nickel-chromium alloy and porcelain," J. Prosth. Dent., 41, 167-172 (1979).

19. D.S. Campbell, "The deposition of thin films by chemical methods," in Handbook of thin film technol$o g y$, L. I. Maissel and R. Glang (eds.), McGraw-Hill, New York, Chapter 5 (1970).

20. R. F. Bunshah, Course notes on evaporation techniques, Materials Department, University of California at Los Angeles.

21. Materials Research Corporation, The basics of sputtering, Materials Research Corp., Orangeburg, NY, (1980)

22. J.E. Varga and W. Bailey, "Evaporation, sputtering, and ion plating: Pros and cons," Solid State Technology, 16, 79-86 (1973).

23. K.J. Anusavice, P.H. Dehoff, and C.W. Fairhurst, "Comparative evaluation of ceramic-metal bond tests using finite element stress analysis," J. Dent. Res., 59, 608 (1980).

24. J.S. Shell and J.P. Nielsen, "Study of the bond between gold alloys and porcelain," J. Dent. Res., 41, 1424 (1962).

25. K. Asgar and Z. Giday, "Refinements on testing of porcelain to metal bond," J. Dent. Res., 57, 292 (1978).

26. J.W. McLean and I. R. Sced, "The bonded aluminal crown. 1. The bonding of platinum to aluminous dental porcelain using tin oxide coatings," Aust. Dent. J., 21, 119-127, (1976).

27. L. A. Allard, "The influence of reactive ion plated oxides on porcelain-metal bonding," Doctoral Thesis, University of Michigan, Ann Arbor, MI (1981).

28. J.T. Bullard, R.D. Dill, V.A. Marker, and E.V. Payne, "Effects of sputtered metal oxide films on the ceramic-to-metal bond," J. Prosthet. Dent., 54, 776-778, (1985).

Received September 23, 1991

Accepted November 10, 1992 